\title{
EXCHANGE AND RETURN OF GOODS OF APPROPRIATE QUALITY PURCHASED REMOTELY: ENFORCEMENT AND THE WILL OF THE LEGISLATOR
}

\author{
Natalya A. Ablyatipova \\ Russian State University of Justice (Crimean Branch), Simferopol, Russian Federation \\ Anastasiya A. Kravtsova \\ Russian State University of Justice (Crimean Branch), Simferopol, Russian Federation
}

\begin{abstract}
Introduction: in the modern world, the sale of goods is increasingly used when using the Internet, which is a kind of remote way of selling goods under a contract of retail sale. In law enforcement practice, this raises the question: in the case where the consumer has purchased the goods remotely, whether he can make a return of such goods, if it is included in the List of non-food goods of good quality, not to be returned or exchanged for similar goods of other size, shape, size, style, color or configuration. In this regard, the authors set a goal: to study the judicial practice and the will of the legislator on this issue. To achieve this goal, the following methods were used: analysis, synthesis, induction, historical and comparative methods. Results: the ratio of the terms for the buyer's refusal of the goods and for the buyer's return of the goods of proper quality for remote purchase and sale is established; the opposite legal positions of the courts on the problem under study are revealed, the conditionality of the relationship with the specific position indicating the possibility of refusal of the consumer as one of the guarantees of his rights is justified. The work has confirmed the fact that this approach was aimed at the will of the legislator. Conclusions: the Relations on the exchange and return of goods purchased remotely have features due to the specifics of the method of purchase and sale. The consumer is a weak point in economic relations, therefore, the legislator reasonably provided additional guarantees of consumer rights: the risk of the consequences of the sale of goods remotely should be covered by the risky nature of business, be assigned to a professional participant in the relationship. The authors suggested that the question of changing this level of guarantees may not occur before the time when the remote relationship between the seller and the buyer will gain established practice, reduce the risks of the consumer, will be higher than the good faith of the parties and (or) will be created technologies for a more complete remote acquaintance, and such relations will achieve such development that will become so common as the relationship of purchase and sale in objective reality, committed in the usual way.

Key words: retail purchase and sale, remote purchase and sale, electronic civil relations, specifics of remote relations, refusal of the consumer of goods of good quality, guarantees of the rights of consumers, risk of consequences of sale of goods by the remote method.
\end{abstract}

Citation. Ablyatipova N.A., Kravtsova A.A. Exchange and Return of Goods of Appropriate Quality Purchased Remotely: Enforcement and the Will of the Legislator. Legal Concept, 2019, vol. 18, no. 1, pp. 123-130. (in Russian). DOI: https://doi.org/10.15688/lc.jvolsu.2019.1.17

\section{ОБМЕН И ВОЗВРАТ ТОВАРОВ НАДЛЕЖАЩЕГО КАЧЕСТВА, ПРИОБРЕТЕННЫХ ДИСТАНЦИОННЫМ СПОСОБОМ: ПРАВОПРИМЕНЕНИЕ И ВОЛЯ ЗАКОНОДАТЕЛЯ}

\author{
Наталья Айдеровна Аблятипова \\ Российский государственный университет правосудия (Крымский филиал), \\ г. Симферополь, Российская Федерация
}




\author{
Анастасия Алексеевна Кравцова \\ Российский государственный университет правосудия (Крымский филиал), г. Симферополь, \\ Российская Федерация
}

\begin{abstract}
Введение: в современном мире все чаще происходит продажа товаров с помощью сети Интернет, которая представляет собой разновидность дистанционного способа продажи товаров по договору розничной купли-продажи. В правоприменительной практике это порождает вопрос: в случае, когда потребитель приобрел товар дистанционным способом, может ли он осуществить возврат предмета, если последний входит в Перечень непродовольственных товаров надлежащего качества, не подлежащих возврату или обмену на аналогичный товар других размера, формы, габарита, фасона, расцветки или комплектации. В связи с этим авторами поставлена цель: исследовать судебную практику и волю законодателя по данному вопросу. Для ее достижения были использованы следующие методы: анализ, синтез, индукция, исторический и сравнительный. Результаты: установлено соотношение сроков для отказа покупателя от товара и для возврата покупателем товара надлежащего качества для дистанционной купли-продажи; выявлены противоположные правовые позиции судов по исследуемой проблеме, аргументирована обусловленная спецификой отношений позиция, указывающая на возможность отказа потребителя как на одну из гарантий его прав. В работе нашло подтверждение то обстоятельство, что именно на такой подход была направлена воля законодателя. Выводы: отношения по обмену и возврату товаров, приобретенных дистанционным способом, обладают особенностями в силу специфики способа осуществления купли-продажи. Потребитель является слабой стороной в экономических отношениях, следовательно законодатель обоснованно предоставил дополнительные гарантии прав потребителя: риск последствий продажи товаров дистанционным способом должен охватываться рисковым характером предпринимательской деятельности, возлагаться на профессионального участника отношений. Авторы высказали предположение, что вопрос об изменении данного уровня гарантий может иметь место не раньше времени, когда дистанционные отношения между продавцом и покупателем обретут устоявшуюся практику, снизятся риски потребителя, будет выше добросовестность сторон и (или) будут созданы технологии для более полного дистанционного ознакомления, и такие отношения достигнут такого развития, что станут настолько обычными, насколько отношения купли-продажи в объективной реальности, совершаемые обычным способом.

Ключевые слова: розничная купля-продажа, дистанционная купля-продажа, электронные гражданские правоотношения, специфика дистанционных отношений, отказ потребителя от товара надлежащего качества, гарантии прав потребителей, риск последствий продажи товаров дистанционным способом.
\end{abstract}

Цитирование. Аблятипова Н. А., Кравцова А. А. Обмен и возврат товаров надлежащего качества, приобретенных дистанционным способом: правоприменение и воля законодателя // Legal Concept $=$ Правовая парадигма. - 2019. - Т. 18, № 1. - C. 123-130. - DOI: https://doi.org/10.15688/lc.jvolsu.2019.1.17

\section{Введение}

В современном мире продажа товаров все чаще происходит с использованием сети Интернет, которая представляет собой разновидность дистанционного способа продажи товаров по договору розничной купли-продажи. В силу своей специфики Интернет открывает не только новые возможности, но ставит перед законодателем и правоприменителем новые правовые вопросы.

Одной из актуальных проблем является вопрос: в случае, когда потребитель приобрел товар дистанционным способом, может ли он осуществить его возврат, если предмет входит в Перечень непродовольственных товаров надлежащего качества, не подлежащих возврату или обмену на анало- гичный товар других размера, формы, габарита, фасона, расцветки или комплектации?

Целью работы является исследование судебной практики и выявление воли законодателя по данному вопросу.

\section{Правовое регулирование дистанционной купли-продажи в аспекте права потребителя на отказ от товара надлежащего качества}

По общему правилу, к отношениям по договору розничной купли-продажи применяется следующее нормативно-правовое предписание, закрепленное в ст. 502 ГК РФ: покупатель наделен правом обменять непродовольственный товар надлежащего качества в четырнадцатидневный срок с момента пере- 
дачи ему такого товара, если необходимый товар для обмена будет отсутствовать, покупатель правомочен возвратить его, если только последний не входит в Перечень непродовольственных товаров надлежащего качества, не подлежащих возврату или обмену на аналогичный товар других размера, формы, габарита, фасона, расцветки или комплектации, утвержденный Постановлением Правительства РФ от 19.01.1998 № 55 (далее - Перечень) [8]. Аналогичное нормативно-правовое предписание содержится в ст. 25 Закона РФ от 07.02.1992 № 2300-1 «О защите прав потребителей» (далее Закон РФ от 07.02.1992 № 2300-1) [6]. Ст. 497 ГК РФ содержит критерии разграничения видов договора розничной купли-продажи: регулирующие продажи товаров по образцам и дистанционный способ продажи товаров; определяющие момент исполнения данных видов договора; закрепляющие право покупателя отказаться от исполнения данных видов договоров до передачи товара. При этом какихлибо указаний на особенности возврата или обмена приобретенных по данным видам договоров товаров статья не содержит [4]. Однако на них указывает п. 4 ст. 26.1 «Дистанционный способ продажи товара» Закона РФ от 07.02.1992 № 2300-1, в котором содержится следующее нормативно-правовое предписание: по общему правилу после передачи товара покупатель может реализовать свое право на отказ в течение семи дней. Более длительный срок установлен для возврата товаров надлежащего качества, когда покупателю в момент доставки не предоставляется информация о порядке и сроках такого возврата, в таком случае срок составляет не более трех месяцев [6]. Таким образом, в данной статье для дистанционного способа продажи устанавливаются два разных срока: 1) для отказа покупателя от товара; 2) для возврата покупателем товара надлежащего качества.

Представляется, что право на отказ покупателя от товара является более широким понятием, чем право на возврат покупателем товара надлежащего качества, поскольку первое понятие представляет собой возможность покупателя отказаться от любого товара, независимо от того, обладает ли он надлежащим качеством. Например, покупатель приобрел товар дистанционным способом, получил товар, в спокойной обстановке детально изучил инструкцию, прилагаемую к последнему, иную информацию, осмотрел в условиях объективной реальности, подумал и пришел к выводу, что товар ему не подходит, и решил отказаться от него по каким-либо субъективным причинам, при этом товар в полном объеме покупатель не эксплуатировал и не может достоверно знать, содержит ли он какие-либо скрытые дефекты, свидетельствующие о ненадлежащем качестве товара. Следовательно, в такой ситуации, если скрытые дефекты имели место быть, покупатель отказывается от товара ненадлежащего качества.

\section{Правовые позиции судов по вопросу реализации права потребителя на отказ от товара \\ при дистанционной купле-продаже}

В судебной практике по исследуемой проблеме сложились две прямо противоположные правовые позиции. Первая заключается в том, что основанием для отказа покупателем от товаров надлежащего качества, входящих в Перечень, не является факт осознания покупателем того, что приобретенный им товар не соответствует его ожиданиям по следующим критериям: размер, форма, габарит, фасон, комплектация; либо осуществления покупателем вывода о том, что товар ему не нравится по указанным критериям. Такая позиция обосновывается судами следующим: возможность обмена или возврата непродовольственного товара надлежащего качества обусловлена видом товара и не ставится в зависимость от способа приобретения, поскольку норма п. 1. ст. 25 Закона РФ от 07.02.1992 № 2300-1, запрещающая обмен товаров, входящих в Перечень, является специальной в отношении нормы, дозволяющей отказ от товара, приобретенного дистанционным способом [2]; указанием на то, что положения ст. 26.1 Закона РФ от 07.02.1992 № 2300-1 не исключают применения Перечня [3]. Указанная позиция преобладает в решениях судов апелляционной и кассационной инстанции в большинстве федеральных округов Российской Федерации. 
Вторая позиция судов по данному вопросу заключается в возможности осуществления потребителем отказа от товара независимо от наличия такого вида товара в Перечне. Практика сложилась таким образом, что эта позиция чаще находит свое отражение в решениях судов первой инстанции, которые впоследствии отменяются вышестоящими судами. Тем не менее существуют и некоторые исключения из общей тенденции. Заслуживает внимания Апелляционное определение Красноярского краевого суда от 09.04.2018 по делу № 33-4301/2018. Суд указал на то, что ст. 26.1 Закона РФ от 07.02.1992 № 2300-1 устанавливает гарантию соблюдения прав потребителей при дистанционной торговле, в частности, права на отказ от товара без объяснения причин в любое время до получения товара, а также в течение семи дней после его получения. Красноярский краевой суд подчеркнул, что ст. 26.1 Закона РФ от 07.02.1992 № 2300-1 прямо не содержит каких-либо запретов на возврат технически сложных товаров, приобретенных дистанционным способом, и, кроме того, не содержит «каких-либо отсылок в Перечне технически сложных товаров либо Перечне товаров надлежащего качества, не подлежащих возврату или обмену» [1].

Представляется, что данная позиция является более обоснованной, а также больше отвечает особенностям дистанционной куплипродажи, обусловленной спецификой отношений продавца и покупателя, которые в настоящее время осуществляются удаленно, посредством сети Интернет. Специфика заключается в следующем: когда потребитель ознакамливается с товаром через его описание и фотоснимок, у него исключена возможность полно и достоверно сформировать представление о товаре в отношении его формы, габарита, фасона, расцветки, поскольку восприятие фотографического изображения объекта и его восприятие в объективной действительности существенно разнятся. Кроме того, потребитель подвержен риску затруднения возможности всецело сформировать представление о товаре по его фотографии в силу несовершенства технического средства в отношении цветопередачи, особенностей его аппаратных настроек либо по причине программного улучшения фотографии (осветления, затенения, из- менения насыщенности цвета фона, наложения фильтров, осуществленных в целях коррекции полученного изображения и повышения его привлекательности для покупателя).

\section{Законодательный процесс по регулированию \\ дистанционной купли-продажи \\ в отношении регламентации права \\ потребителя на отказ от товара}

Следует отметить, что, поскольку правоприменительная практика не дает однозначного ответа на вопрос о возможности или невозможности отказа от товара надлежащего качества, входящего в Перечень, является необходимым анализ того, на что была направлена воля законодателя при создании положений ст. 26.1 Закона РФ от 07.02.1992 № 2300-1 во время правотворческого процесса по проекту Федерального закона № 388132-3 [7].

В пояснительной записке к данному законопроекту указывалось, что он предполагает усиление ответственности за нарушение прав потребителей, своей целью ставит обеспечение баланса между интересами потребителей и предпринимателей, основная часть изменений и дополнений направлена «на усиление гарантий реализации прав потребителей, предоставленных действующим Законом», «в Проект включены положения, обеспечивающие защиту прав потребителей при осуществлении продажи товаров дистанционным способом» [9]. Между тем в самой пояснительной записке существует некоторое нарушение смыслового единства. С одной стороны, в ней говорится, что необходимо обеспечить баланс интересов предпринимателей и потребителей, и в этих целях является необходимым ограничение права на расторжение договора купли-продажи дистанционным способом, если объектом по такому договору выступает технически сложный или дорогостоящий товар; реализовать указанное право в отношении таких объектов можно только при наличии существенного недостатка. Объясняется это тем, что в ситуации расторжения договора при недостатке, не носящем существенного характера в случае с такими специфическими объектами, убытки и характер недостатков несоизмеримы. С другой стороны, в пояснительной записке подчер- 
кивается, что потребители-граждане являются «наиболее слабым субъектом на товарном рынке» и в отношении них «необходимо установление дополнительных гарантий соблюдения их прав» [9].

В соответствии с этой логикой в первоначальном тексте внесенного в Государственную Думу законопроекта ст. 26.1 содержала нормативно-правовое предписание о том, что потребитель может отказаться от товара до его передачи, после передачи - в течение десяти дней, кроме того, предусматривалось ограничение в отношении товаров, изготовленных по заказу потребителя в целях исключительно индивидуального использования, а также отсылка к Перечню товаров, не подлежащих возврату, утвержденному Правительством.

Однако на этапе рассмотрения законопроекта Государственной Думой во втором чтении в заключении Правового управления была изложена позиция, что ограничение права потребителя на отказ от товара надлежащего качества в отношении дистанционного способа приобретения такого товара не отвечает целям проекта, а именно усилению гарантий реализации прав потребителей. Правовое управление подчеркнуло, что дистанционный способ приобретения товаров удобен и доступен и ограничения могут негативно сказаться на категории социально незащищенных граждан, в число которых входят малообеспеченные; указало на необходимость дополнительного обсуждения данных положений [5].

На этапе второго чтения при принятии ответственным комитетом решения о предоставлении законопроекта в Совет Государственной Думы из текста проекта в ст. 26.1 была исключена отсылка к Перечню товаров, не подлежащих возврату, утвержденному Правительством [10]. По результатам правотворческой работы был принят закон, не содержащий в ст. 26.1 ограничений, рассматриваемых прав потребителей. Следовательно, можно сделать вывод, что воля законодателя направлена на установление дополнительных гарантий прав потребителей и его право на отказ от товара надлежащего качества, приобретенного дистанционным способом, не ограничивается запретом ст. 25 Закона РФ от
07.02.1992 № 2300-1 в отношении товаров, включенных в Перечень.

\section{Выводы}

Таким образом, отношения по обмену и возврату товаров, приобретенных дистанционным способом, обладают особенностями в силу специфики способа осуществления купли-продажи. Данная специфика, которая имеет место в силу научно-технического и информационного развития общества, создает трудности в установлении правового регулирования и правоприменении. Поскольку, с одной стороны, существуют экономические интересы предпринимателя, в целом защищающиеся при регулировании розничной купли-продажи в отношении исключения убытков, которые он может понести при транспортировке и передаче товаров, включенных в Перечень. С другой стороны, существуют интересы потребителя, который является слабым субъектом экономических отношений, законодатель конструирует его правовое положение исходя из того, что он не обладает и не должен обладать специальными знаниями, быть профессиональным участником отношений.

Поэтому, заключая договор розничной купли-продажи дистанционным способом, обе стороны рискуют (и продавец, и покупатель) в силу того, что способ специфический. Представляется, что, разрешая вопрос о том, на кого возложить последствия такого риска, законодатель обоснованно предоставил дополнительные гарантии прав потребителя в ст. 26.1 Закона РФ от 07.02.1992 № 2300-1: предпринимательская деятельность в силу положений Гражданского кодекса Российской Федерации, носит рисковый характер, поэтому риск последствий продажи товаров дистанционным способом должен им охватываться.

В настоящее время наиболее распространена дистанционная купля-продажа посредством сети Интернет по причинам удобности и доступности, однако эти отношения несут еще больше угроз для потребителя как для слабой стороны. Возможно, в будущем устоится практика дистанционных отношений между продавцом и покупателем, такой способ купли-продажи станет нести меньше рисков для потребителя, будет выше добросовест- 
ность сторон и (или) будут созданы технологии для более полного дистанционного ознакомления, и эти отношения достигнут такого развития, что станут настолько обычными, как отношения купли-продажи в объективной реальности, совершаемые обычным способом; лишь при таких условиях можно будет поставить вопрос о том, насколько существенными являются для потребителя характеристики товара в отношении расцветки, фасона, формы в сравнении с убытками, которые рискует понести продавец при отказе потребителя от товара надлежащего качества.

\section{СПИСОК ЛИТЕРАТУРЫ}

1. Апелляционное определение Красноярского краевого суда от 09.04.2018 по делу № 33-4301/2018. Доступ из справ.-правовой системы «КонсультантПлюс».

2. Апелляционное определение Московского городского суда от 26.05.2015 по делу № 33-17875. Доступ из справ.-правовой системы «КонсультантПлюс».

3. Апелляционное определение Санкт-Петербургского городского суда от 22.05.2018 № 3310386/2018 по делу № 2-8289/2017. - Доступ из справ.-правовой системы «КонсультантПлюс».

4. Гражданский кодекс Российской Федерации (часть вторая) от 26.01.1996 № 14-Ф3 (ред. от 29.07.2018). - Доступ из справ.-правовой системы «КонсультантПлюс».

5. Заключение ПУ Аппарата ГД ФС РФ от 28.10.2004 № 2.2-1/3533 «По проекту Федерального закона № 388132-3 “О внесении изменений в Закон Российской Федерации “О защите прав потребителей” и о признании утратившим силу пункта 28 статьи 1 Федерального закона “О внесении изменений и дополнений в Закон Российской Федерации “О защите прав потребителей”» (II чтение). - Доступ из справ.-правовой системы «КонсультантПлюс».

6. Закон РФ от 07.02.1992 № 2300-1 (ред. от 04.06.2018) «О защите прав потребителей». - Доступ из справ.-правовой системы «КонсультантПлюс».

7. Паспорт проекта Федерального закона № 388132-3 «О внесении изменений в Закон Российской Федерации "О защите прав потребителей” и о признании утратившим силу пункта 28 статьи 1 Федерального закона "О внесении изменений и дополнений в Закон Российской Федерации “О защите прав потребителей” (в части усиления гарантий реализации прав потребителей в связи с принятием законов, направленных на снятие администра- тивных барьеров в экономике и защиту малого бизнеса)» (внесен Правительством РФ) (подписан Президентом РФ). - Доступ из справ.-правовой системы «КонсультантПлюс».

8. Постановление Правительства РФ от 19.01 .1998 № 55 (ред. от 30.05.2018) «Об утверждении Правил продажи отдельных видов товаров, перечня товаров длительного пользования, на которые не распространяется требование покупателя о безвозмездном предоставлении ему на период ремонта или замены аналогичного товара, и перечня непродовольственных товаров надлежащего качества, не подлежащих возврату или обмену на аналогичный товар других размера, формы, габарита, фасона, расцветки или комплектации». - Доступ из справ.-правовой системы «КонсультантПлюс».

9. Пояснительная записка «К проекту Федерального закона "О внесении изменений и дополнений в Закон Российской Федерации “О защите прав потребителей” и часть вторую Гражданского кодекса Российской Федерации». - Доступ из справ.-правовой системы «КонсультантПлюс».

10. Проект Федерального закона № 388132-3 «О внесении изменений в Закон Российской Федерации “О защите прав потребителей” и о признании угратившим силу пункта 28 статьи 1 Федерального закона “О внесении изменений и дополнений в Закон Российской Федерации “О защите прав потребителей”» (ред., подготовленная ГД ФС РФ ко II чтению 17.11.2004). - Доступ из справ.-правовой системы «КонсультантПлюс».

\section{REFERENCES}

1. Apellyatsionnoe opredelenie Krasnoyarskogo kraevogo suda ot 09.04.2018 po delu № 33-4301/2018 [Appeal Determination of the Krasnoyarsk Regional Court April 09, 2018 in the Case No. 33-4301/2018]. Access from Reference Legal Sistem 'Consultant Plus'.

2. Apellyatsionnoe opredelenie Moskovskogo gorodskogo suda ot 26.05.2015 po delu № 33-17875 [Appeal Determination of the Moscow City Court May 26, 2015 in the Case No. 33-17875]. Access from Reference Legal Sistem 'Consultant Plus'.

3. Apellyatsionnoe opredelenie SanktPeterburgskogo gorodskogo suda ot 22.05.2018 № 33-10386/2018 po delu № 2-8289/2017 [Appeal Determination of the St. Petersburg City Court May 22, 2018 No. 33-10386/2018 in the Case No. 2-8289/ 2017]. Access from Reference Legal Sistem 'Consultant Plus'.

4. Grazhdanskiy kodeks Rossiyskoy Federatsii (chast vtoraya) ot 26.01.1996 № 14-FZ (red. ot 29.07.2018) [The Civil Code of the Russian Federation (Part two) Federal Law of January 26, 1996 
No. 14-FL (as amended from July 29, 2018)]. Access from Reference Legal Sistem 'Consultant Plus'.

5. Zaklyuchenie PU Apparata GD FS RF ot 28.10.2004 № 2.2-1/3533 «Po proektu Federalnogo zakona № 388132-3 "O vnesenii izmeneniy v Zakon Rossiyskoy Federatsii "O zashchite prav potrebiteley" $i$ o priznanii utrativshim silu punkta 28 stati 1 $F e d e r a l n o g o$ zakona "O vnesenii izmeneniy $i$ dopolneniy v Zakon Rossiyskoy Federatsii " $O$ zashchite prav potrebiteley" (II chtenie) [The Conclusion of a Legal Department of the Apparatus of the State Duma of the Federal Assembly of the Russian Federation October 28, 2004 No. 2.2-1/3533 'On the draft Federal Law No. 388132-3 'On amendments to the Law of the Russian Federation 'About Protection of the Rights of Consumers' and about Acknowledgement become Invalid for Point 28 of Article 1 of the Federal Law 'About Modification and Additions in the Law of the Russian Federation 'On Protection of Consumer Rights' (Second Reading)] . Access from Reference Legal Sistem 'Consultant Plus'.

6. Zakon RF ot 07.02.1992 № 2300-1 (red. ot 04.06.2018) «O zashchite prav potrebiteley» [The Law of the Russian Federation February 7, 1992 No. 2300-1 (as amended from June 4, 2018) 'On Consumer Rights Protection']. Access from Reference Legal Sistem 'Consultant Plus'.

7. Pasport proekta Federalnogo zakona № 388132-3 «O vnesenii izmeneniy v Zakon Rossiyskoy Federatsii "Ozashchite prav potrebiteley" $i$ o priznanii utrativshim silu punkta 28 stati 1 Federalnogo zakona "O vnesenii izmeneniy i dopolneniy v Zakon Rossiyskoy Federatsii "O zashhite prav potrebiteley" (v chasti usileniya garantiy realizatsii prav potrebiteley $v$ svyazi $s$ prinyatiem zakonov, napravlennykh na snyatie administrativnykh barerov $v$ ekonomike $i$ zashchitu malogo biznesa)» (vnesen Pravitelstvom RF) (podpisan Prezidentom RF) [Passport of the draft Federal Law No. 388132-3 'On amendments to the Law of the Russian Federation 'On Protection of Consumers 'Rights' and on the Recognition as Invalid Paragraph 28 of Article 1 of the Federal Law 'On Amendments and Additions to the Law of the Russian Federation 'On Protection of Consumers' Rights (in Terms of Strengthening Guarantees for the Implementation of Consumer Rights in Connection with the Adoption of Laws Aimed at Removing Administrative Barriers in the Economy and Protection of Small Business)' (Submitted by the Government of the Russian Federation) (Signed by the President of the Russian Federation)]. Access from Reference Legal Sistem 'Consultant Plus'.
8. Postanovlenie Pravitelstva RF ot 19.01.1998 № 55 (red. ot 30.05.2018) «Ob utverzhdenii Pravil prodazhi otdelnykh vidov tovarov, perechnya tovarov dlitelnogo polzovaniya, na kotorye ne rasprostranyaetsya trebovanie pokupatelya o bezvozmezdnom predostavlenii emu na period remonta ili zameny analogichnogo tovara, i perechnya neprodovolstvennykh tovarov nadlezhashchego kachestva, ne podlezhashchikh vozvratu ili obmenu na analogichnyy tovar drugikh razmera, formy, gabarita, fasona, rastsvetki ili komplektatsii» [The Order of the Government of the Russian Federation January 19, 1998 No. 55 (edition of May 30, 2018) 'About the Approval of Rules of Sale of Separate Types of Goods, the List of Durable Goods on which the Requirement of the Buyer about Gratuitous Providing to it for the Period of Repair or Replacement of Similar Goods, and the List of the Nonfood Goods of Appropriate Quality which are not Subject to Return or Exchange for Similar Goods of Other Size, the Form, the Size, the Style, Coloring or a Complete Set Does Not Extend']. Access from Reference Legal Sistem 'Consultant Plus'.

9. Poyasnitelnaya zapiska «K proektu $F e d e r a l n o g o$ zakona "O vnesenii izmeneniy $i$ dopolneniy $v$ Zakon Rossiyskoy Federatsii "O zashhite prav potrebiteley" $i$ chast vtoruyu Grazhdanskogo kodeksa Rossiyskoy Federatsii"” [Explanatory Note 'To the Draft Federal Law' on Amendments and Additions to the Law of the Russian Federation 'On Consumer Protection' and to the Civil Code of the Russian Federation part two']. Access from Reference Legal Sistem 'Consultant Plus'.

10. Proekt Federalnogo zakona № 388132-3 «O vnesenii izmeneniy $v$ Zakon Rossiyskoy Federatsii "O zashhite prav potrebiteley" $i$ o priznanii utrativshim silu punkta 28 stati 1 Federalnogo zakona "O vnesenii izmeneniy $i$ dopolneniy v Zakon Rossiyskoy Federatsii "O zashhite prav potrebiteley" (red., podgotovlennaya GD FS RF ko II chteniyu 17.11.2004) [The Draft Federal Law No. 388132-3 'On Amendments to the Law of the Russian Federation 'On Protection of Consumers 'Rights' and on Invalidation of Paragraph 28 of Article 1 of the Federal Law 'On Amendments and Additions to the Law of the Russian Federation 'On Consumer Protection' (ed., prepared by the State Duma of the Russian Federation to II reading November 17, 2004)]. Access from Reference Legal Sistem 'Consultant Plus'. 


\section{ВОПРОСЫ ЧАСТНОПРАВОВОГО РЕГУЛИРОВАНИЯ}

\section{Information about the Authors}

Natalya A. Ablyatipova, Candidate of Sciences (Jurisprudence), Associate Professor, Honored lawyer of the Republic of Crimea, Russian State University of Justice (Crimean Branch), Pavlenko St., 5, 295006 Simferopol, RussianFederation, ve_na2014@mail.ru, mail@crb.rsuj.ru, https://orcid.org/0000-0002-4579-3871

Anastasiya A. Kravtsova, student, Russian State University of Justice (Crimean Branch), Pavlenko St., 5, 295006 Simferopol, Russian Federation, nastia.kravtsova@gmail.com,mail@crb.rsuj.ru, https://orcid.org/0000-0001-9754-0836

\section{Информация об авторах}

Наталья Айдеровна Аблятипова, кандидат юридических наук, доцент, заслуженный юрист РК, Российский государственный университет правосудия (Крымский филиал), ул. Павленко, 5, 295006 г. Симферополь, Российская Федерация, ve_na2014@mail.ru, mail@crb.rsuj.ru, https://orcid.org/0000-0002-4579-3871

Анастасия Алексеевна Кравцова, студент, Российский государственный университет правосудия (Крымский филиал), ул. Павленко, 5, 295006 г. Симферополь, Российская Федерация, nastia.kravtsova@gmail.com,mail@crb.rsuj.ru,https://orcid.org/0000-0001-9754-0836 